\title{
EFFECT OF EXERCISE AND MANUAL PHYSICAL THERAPY ON SHOULDER FUNCTION AMONG SLAUGHTERHOUSE WORKERS WITH SHOULDER IMPINGEMENT SYNDROME.
}

\author{
By \\ El-Laithy N.; El-Toukhy M.A.*; Amar H.A.* and Asal N.M.** \\ FROM \\ Community, Environmental \& Occupational Medicine, Rheumatology \\ \&Rehabilitation* and Radiology** Departments \\ Faculty of Medicine, Zagazig University.
}

\begin{abstract}
This study was carried out in a slaughterhouse in Zagazig City during the year 2005-2006 among a group of 115 slaughterhouse workers selected randomly and performing sustained intensive manual work. Another group of 80 clerks working in Zagazig Faculty of medicine performing light manual work was selected randomly as a control group.

The study was done in 2 stages : The 1st stage was a comparative cross-sectional study, aiming to determine the prevalence of shoulder impingement syndrome ( SIS) among the study workers.

The 2nd stage was an intervention study, done to assess the effect of exercise and manual physical therapy program on shoulder function among workers with shoulder impingement syndrome. A total number of one-hundred and ninety five workers were interviewed using a preconstructed questionnaire. Those workers who had recurrent
\end{abstract}


shoulder pain during the previous 3 months or more were subjected to standardized physical examination using impingement sign, assessment of shoulder function and magnetic resonance imaging to those clinically diagnosed as SIS. Also an intervention program of exercise and manual therapy for a period of 6-weeks was carried out to those workers with SIS.

The results revealed that the prevalence of SIS was higher among the slaughterhouse workers $(13.9 \%)$ compared to the control workers(2.5\%). SIS symptoms and signs were more frequently recorded among the slaughterhouse workers when compared with the controls. Also among those currently complaining of SIS symptoms or those who has had SIS signs, only $15.6 \%$ and $2.5 \%$ have positive impingement sign among slaughterhouse workers and their controls respectively.

The most reliable findings of magnetic resonance imaging were the presence of indentations upon the subacromial fat denoting impingement in 12 patients $(66.7 \%)$, supraspinatus tendonitis with indentation upon subacromial fat denoting impingement in 4 patients $(22.2 \%)$ \& left supraspinatus tear in 2 patients (11.1\%) from 18 slaughterhouse workers diagnosed clinically as SIS and supraspinatus tendonitis with impingement in 2 patients (100.0\%) from the control group with a total percentage of $13.9 \%$ and $2.5 \%$ workers with SIS among slaughterhouse workers and their controls respectively. Studying some personal and occupational factors thought to be related to the prevalence of SIS revealed that, SIS was prevalent in middle aged workers who smoke and were worked in the current occupation for more than ten years.

The results of the intervention program illustrated that there were significant improvement in range of motion, pain, strength and function of the shoulder in workers with SIS after 6- weeks of exercise and manual physical therapy program.

In conclusion, sustained intensive manual work such as in slaughterhouse workers was associated with high frequency of SIS. A 6 week exercise with manual physical therapy program in patients with SIS was resulted in improvement of range of motion, pain and function of the shoulder. So, work organization especially reduction of exposure time and early intervention are needed in tasks in which there are combinations of force, repetition and sustained arm elevation. 


\section{Introduction}

The term "shoulder Impingement" was introduced by Neer ${ }^{(1)}$ and refers to the compression of the rotator cuff [four muscles which control 3 basic shoulder movements, abduction, internal and external rotation (fig.1)], subacromial bursa, and biceps tendon against the anterior undersurface of the acromion and coracoacromial ligament especially during elevation of the $\operatorname{arm}^{(2)}$.Most authers believe shoulder impingements are the most common cause of shoulder pain and there is general consensus that impingement is the primary underlying problem or at least a migrating factor in many rotator cuff dis$\operatorname{orders}^{(3,4)}$ especially rotator cuff tears ${ }^{(5,6)}$.

Multiple factors have been proposed to contribute to the development of shoulder impingement syndrome(SIS).These factors include a number of anatomical variation as abnormal acromion morphology ${ }^{(7,8)}$, capsular abnormalities ${ }^{(9,10,11)}$ (primary impingement), poor posture ${ }^{(12,13,14)}$ and overuse injury secondary to repetitive motion of the arms, repetitive eccentric load- ing or sustained use of the arm above 90 degrees of elevation (secondary impingement $)^{(12,13,14,15)}$. All these factors decrease the subacromial space with subsequent increasing the potential risk of impingement ${ }^{(16,17)}$.

SIS is especially frequent in occupations with overuse arm activity as construction work $^{(18)}$, repetitive assembly line work $^{(19)}$, supermarket cashiers ${ }^{(20)}$, clothing $^{(21)}$, slaughtering ${ }^{(22)}$ and fish processing $^{(23)}$

Because impingement syndrome is believed to contribute to the tearing of the rotator cuff $^{(4)}$, early identification of impingement and intervention are desirable . The variation in intervention approaches is directly related to various views on the mechanism leading to impingement ${ }^{(24)}$.

The aim of this work was to study the prevalence of SIS among the slaughterhouse workers and to identify changes that occur in functional outcome in workers with impingement syndrome following exercise and manual therapy program. 

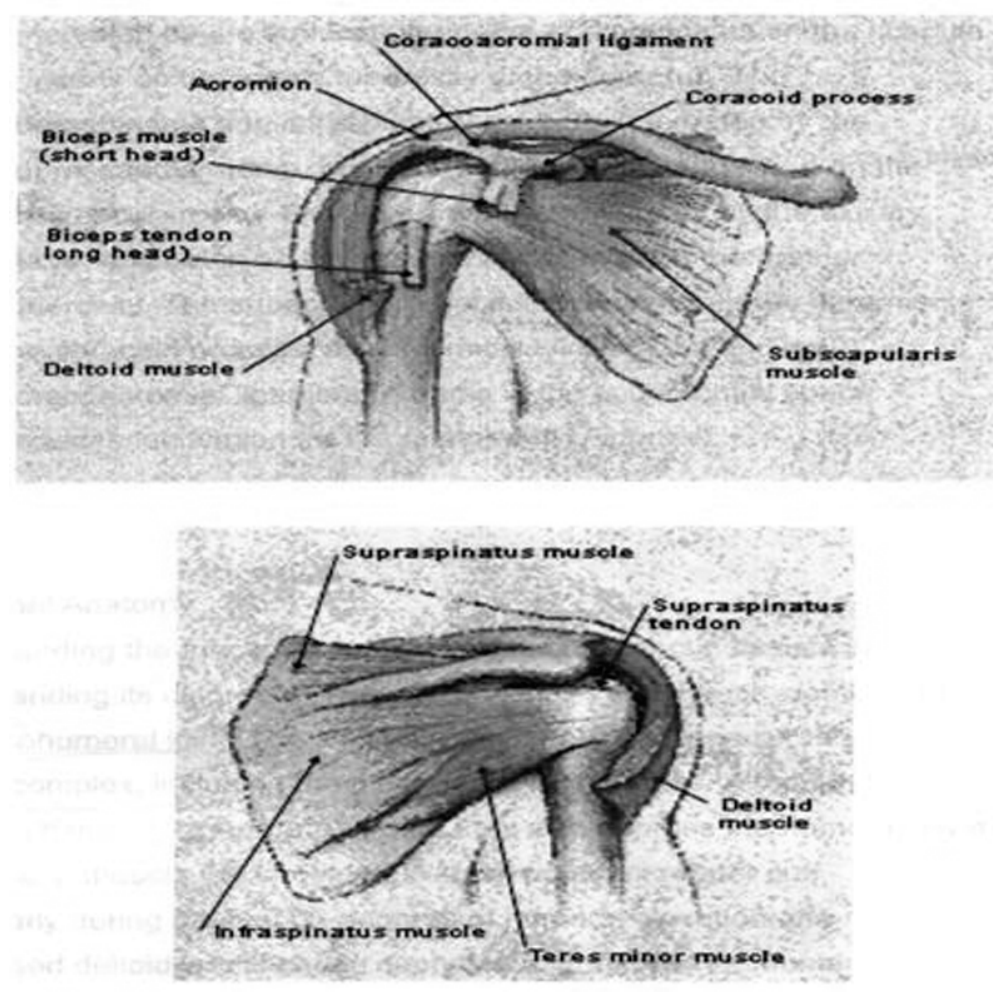

Fig 1: Anatomy of the shoulder and rotator cuff, showing (left) anterior and (right) posterior view ${ }^{(2)}$.

\section{Subjects \& Methods}

\section{Subjects:}

This study was conducted at a slaughterhouse in Zagazig City during the period from November 2005 to July 2006 among 115 male slaughterhouse workers were selected randomly and performing sustained intensive manual work. Another group of 80 male clerks working in Zagazig Faculty of Medicine performed light manual work was selected randomly and considered as the control group. The study was performed in two stages:

The $1^{\text {st }}$ stage was a comparative crosssectional study, aiming at estimation of the shoulder impingement prevalence among the study groups.

The $2^{\text {nd }}$ stage was an intervention study in which workers with SIS were subjected to exercise and manual therapy program for a period of 6-weeks. 


\section{Exclusion Criteria :}

Subjects with any of the following medical conditions that could possibly be associated with shoulder disorders of non occupational origin were excluded from the study as rheumatoid arthritis, gout, myasthenia gravis, hemiplegia, diabetes, fracture of the clavicle, humerus or scapula, dislocation of the glenohumeral joint or the clavicular joints, atrophic upper limb after trauma or sequelae after poliomyelitis.

\section{Methods:}

In the $1^{\text {st }}$ stage (cross-sectional) informations on exposure and health were collected with questionnaire, ergonomic observations of tasks, standardized physical examination and magnetic resonance imaging (MRI).

1.Questionnaire: Through the use of selfadministered questionnaire and personal interviews ,data were collected regarding:

A. personal history: Such as age, smoking habit, weight and height. The body mass index (BMI) was calculated and expressed in $\mathrm{kg} / \mathrm{m}^{2}$.

B. Occupational history: Included number of years worked in current occupation, average hours worked / day, posture and motion of the upper arms during work and history of previous occupations.

C. Complaint and present history: Symptoms of SIS included the following :

-Pain during abduction

-Pain located in the proximal lateral aspect of upper arm.

Information on self-reported shoulder symptoms was collected with slightly modified questions from the Standardized Nordic Musculoskeletal Questionnaires ${ }^{(25)}$

2. Exposure Assessment: Beside information on the occupation taken from the questionnaire, self-reported observations of the tasks held by slaughterhouse workers, described previously as being monotonous and highly intensive manually(22),were performed during the working days in a random sample of workers. These observations showed that their upper arms were raised to at least 30 degrees for nearly half the working time and the arms were raised above 30 degrees about 10 times a minute. Repetitive manual movements were also reported for at least half the day by about $2 / 3$ of the slaughterhouse workers, while workers in the control group performed light manual work in the form of writing, revising, and doing calculation while sitting on chairs. 
3. Health Assessment: Beside the information on SIS symptoms obtained from the questionnaire, subjects reporting recurrent shoulder pain or discomfort during the previous 3 months or more within the past year were selected for :

-Standardized physical examination: confirmed the diagnosis of impingement by having at least 3 of the following ${ }^{(26)}$ :

1. Pain with active shoulder abduction.

2. Pain at resisted abduction of the arm.

3 . Tenderness of the greater humeral tubercle.

4. Positive impingement $\operatorname{sign}^{(16,22,27)}$ : positive when pain at the anterolateral and superior aspect of the shoulder joint could be elicited or exacerbated by passive internal rotation of the arm in 90 degrees shoulder abduction in the plane of the scapula

5. Pain in the $\mathrm{C} 5$ or $\mathrm{C} 6$ dermatome.

-Assessment of shoulder function: to all workers, as proposed by Constant ${ }^{(28)}$.

This scoring system (100 points) consists of four variables that are used to assess the shoulder function. The subjective variables are pain (15points) and activities [sleep, work, recreation, sports (20 points)] which give a total of 35 points.
The objective variables are range of motion (40 points) and strength (25 points) which give a total score of 65 points.

Range of movement: According to Constant score, measuring the range of motion done with the patient sitting on a chair or bed with weight even distributed between the ischeal tuberosities. No Rotation of the upper body may take place during the examination .Active and passive range of motion was measured using a standard goniometer. In the case of active motion, the patient lift his arm to a pain free level .Note that the number of degrees at which the pain starts determines the range of motion .The Constant Score can not be applied beyond the initiation of pain :

1-Forward flexion:.........................10 points

2-Abduction:....................................10 points

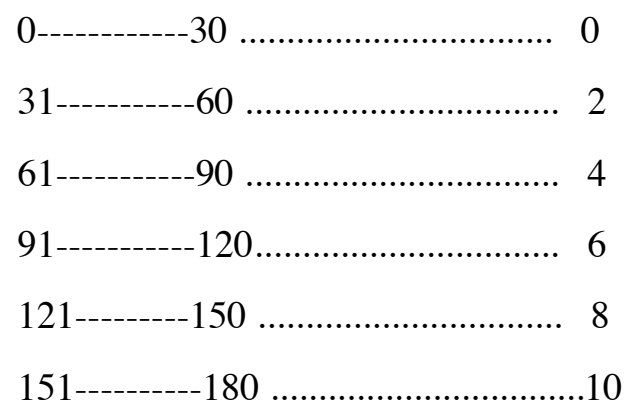

\section{3-External rotation .....................10 points}

(hand is not allowed to touch the head).

-Not reaching head 
-Hand behind head with elbow forward......2 -Hand behind head with elbow back...........2

-Hand on top of head with elbow forward...2 -Hand on top of head with elbow back..... .2

-Full elevation from on top of head...........2

\section{4-Internal rotation:} . .10 points

-End of thumb to later of thigh .0

-End of thumb to buttock..............................2

-End of thumb to lumbosacral joint............ 4

-End of thumb to L3 (waist)........................6

-End of thumb to T12 ....................................

-End of thumb to T7 (under scapular)........10

Strength: Strength is given a maximum of 25 points in the Constant score using spring balance.

The European Society for Shoulder and Elbow Surgery measures Strength according to the following method:

* A spring balance is attached distal on the forearm.

* Strength is measured with the arm is 90 degrees of elevation in the plane of the scapula ( 30 degrees in front of the coronal plane) and elbow straight.

* Palm of the hand facing the floor (pronation).

* The patient is asked to maintain this resisted elevation for 5 seconds.
* It is repeated 3 times immediately after another.

* The average in pound (lb) is noted.

* The measurement should be pain free. If pain is involved the patient gets 0 points.

* If patient is unable to achieve 90 degrees of elevation of the scapula plane the patient gets 0 points.

Strength is measured in the following directions :

\section{-Forward flexion}

\section{-Abduction}

-Internal rotation in 0 degrees of abduction.

-External rotation in 0 degrees of abduction.

Strength is graded as follows:

-No contractions. .0

-Flicker 1

-Movement with gravity eliminated............2

-Movement against gravity............................ 3

-Movement against some resistance.............4

-Normal power...............................................

\section{-Magnetic Resonance Imaging (MRI):}

MR imaging of the shoulder was performed for all symptomatic clinically diagnosed SIS cases $(\mathrm{N}=20)$ at the Radiology 
Department of Zagazig University Hospital. The patient is positioned supine with the arm extended in neutral .The arm is separated from thorax with a sponge to avoid respiratory movements surface coils are mandatory. The use of dedicated surface coil is recommended (phase-array coils improve signal to noise ratio (SNR) and contrast resolution). We begin the study with an axial plane multiplanar 2D gradient echo (GE) T2 WT (SE) or frost FSE .The angle of acqulisition of the coronal oblique images should be determined using bony glenoid as a landmark sagittal oblique T,WI are obtained parallel to the glenoid to elevate the acromioclavicular joint and coracoacromial arch .Fat suppression and SIIR techniques have several advantages including improved depiction of bone marrow abnormalities ,improved distinction between fat and fluid , and reduction of chemical shift and respiratory and motion artifact ${ }^{(29)}$.

\section{4-Intervention Study:}

In the 2nd stage (intervention), a total number of 18 workers who diagnosed as SIS were initially recruited and subjected to 6-week exercise with manual physical therapy program at Rheumatology \& Rehabilitation Department Faculty of Medicine Zagazig University aimed at strengthening the rotator cuff and increasing the flexibility of the posterior glenohumeral capsule. This program consisted of supervised and home parts of strengthening and flexibility exercises ${ }^{(2)}$ with manual physical therapy included passive joint mobilization, massage or muscle stretching technique $^{(30)}$ in which each subject attended 3 physical therapy session per week for a 6week period. Assessment of shoulder function by Constant score being taken before and after a 6-week intervention period. After intervention, eight workers did not complete the 6-week exercise program and follow-up testing leaving a total of 12 workers. Those subjects who did not complete the study cited either scheduling problems or personal circumstance that prevented weekly visits or they simply did not return and did not give an explanation.

\section{Statistical Analysis}

Collected data were analyzed using Statistical Package for Social Sciences (SPSS) computer program (version 9.0) for windows ${ }^{(31)}$. The significance of differences between the study variables was evaluated by Chi-square $\left(\mathrm{X}^{2}\right)$, Fisher exact and student,s t- tests. Paired t-test was used for comparisons between before and after means. ANOVA (one-way analysis of variances) and Least Significant Difference (LSD) tests were used for comparisons between multiple group means. 
Odd's ratios (ORs) and their 95\% confidence intervals $(95 \% \mathrm{CI})$ were also calculated. The significance level was considered at $\mathrm{P}$-value $<0.05$

\section{Results}

Table (1) demonstrates the distribution of the study workers according to age ,BMI, smoking habit and duration of work . There were no significant differences between the two groups with regard to their characteristics .

Table (2) shows that the prevalence of SIS was significantly higher among the slaughterhouse workers (13.9\%) when compared to clerks $(2.5 \%)$.

Table (3) illustrates that SIS symptoms and signs were significantly more frequent among slaughterhouse workers compared to their controls. More than one fourth of the slaughterhouse workers $(27.8 \%)$ complained of SIS symptoms compared to $12.5 \%$ of the controls. Also 19.1\%, 22.6\% and $8.7 \%$ of the slaughterhouse workers has had pain at resisted arm abduction, tenderness over greater humeral tubercle and pain in the $\mathrm{C} 5$ or $\mathrm{C} 6$ dermatome compared to $7.5 \%, 10.5 \%$ and $1.25 \%$ in the control group respectively. The same table shows that, among those currently complaining of SIS symptoms or those who had other SIS signs, only $15.6 \%$ and $2.5 \%$ have positive impingement sign among slaughterhouse workers and their controls respectively.

Table (4) shows that the total score of shoulder function and the score for pain \& activities, range of motion and strength were significantly lower among workers with diagnosed SIS than among healthy workers and workers with SIS symptoms in both the study workers. While there were no differences between healthy workers and workers with SIS symptoms as regard the score of shoulder function.

The MRI findings (table 5) show the presence of mild to moderate indentations upon subacromial fat due to muscle impingement (fig 2) in 12 patients $(66.6 \%$ ) from 18 slaughterhouse workers clinically diagnosed as SIS. Also evidence of intermediate signal intensity involving the supraspinatus tendon denoting tendonitis appear in MRI accompanied with indentation upon subacromial fat denoting impingement in 4 patients $(22.2 \%)$ from 18 slaughterhouse workers (fig.3) and two patients (100.0\%) from control workers clinically diagnosed as SIS with a total percentage of $13.9 \%$ and $2.5 \%$ with SIS among slaughterhouse workers and controls respectively. Another 2 cases were diagnosed also by MRI as left supraspinatus tear among 18 slaughterhouse workers(11.1\%) with positive impingement sign. 
Studying of some personal and occu- the current occupation for more than ten pational risk factors which may be related years. The results of our intervention proto SIS, table (6) reveals that, age, smoking gram (table 7) illustrate that a significant and duration of work had significant ef- improvement in range of motion, pain, fects on the occurrence of SIS. Thus, SIS strength and function of the shoulder was was found to be prevalent in middle aged noticed in workers with SIS after 6- weeks workers who smoke and were worked in of exercise and manual physical therapy.

Table (1): General characteristics of the study workers

\begin{tabular}{|lc|c|c|c|}
\hline \multicolumn{2}{|c|}{ Characteristics } & \multicolumn{1}{|c|}{$\begin{array}{c}\text { Slaughterhouse } \\
\text { Workers } \\
\mathrm{N}=115\end{array}$} & $\begin{array}{c}\text { Control } \\
\text { Workers } \\
\mathrm{N}=80\end{array}$ & P-value \\
\hline Age (y) & $\mathrm{X} \pm \mathrm{SD}$ & $40.3 \pm 6.1$ & $39.2 \pm 5.1$ & $>0.05$ \\
\hline Smoking habit & $\mathrm{No}(\%)$ & $64(55.7)$ & $35(43.7)$ & $>0.05$ \\
\hline BMI $\left(\mathrm{Kg} / \mathrm{M}^{2}\right)$ & $\mathrm{X} \pm \mathrm{SD}$ & $27.1 \pm 4.04$ & $25.9 \pm 6.29$ & $>0.05$ \\
\hline Duration of work & $\mathrm{X} \pm \mathrm{SD}$ & $17.1 \pm 4.13$ & $15.8 \pm 6.31$ & $>0.05$ \\
\hline
\end{tabular}

Table (2): Prevalence of Shoulder impingement syndrome (SIS) among the study workers.

\begin{tabular}{|l|c|c|c|}
\hline \multirow{2}{*}{ Study Group } & \multirow{2}{*}{ Total } & $\begin{array}{c}\text { Prevalence } \\
\text { of SIS }\end{array}$ & \multirow{2}{*}{ OR (95\%CI) } \\
\cline { 3 - 3 } & & No (\%) & \\
\hline Clerks & 80 & $2(2.5)$ & 1.0 \\
\hline Slaughterhouse workers & 115 & $16(13.9)$ & $6.30(1.40-57.73)^{*}$ \\
\hline
\end{tabular}

$* \mathrm{P}<0.01$ 
Table (3): Distribution of symptoms and signs among the study workers.

\begin{tabular}{|l|c|c|c|c|}
\hline \multirow{2}{*}{ Symptoms and signs } & $\begin{array}{c}\text { Slaughterhouse } \\
\text { Workers } \\
\mathrm{N}=115\end{array}$ & $\begin{array}{c}\text { Control } \\
\text { Workers } \\
\mathrm{N}=80\end{array}$ & $\mathrm{X}^{2}$ & P-value \\
\cline { 2 - 3 } & No (\%) & No (\%) & & \\
\hline Symptoms: & $32(27.8)$ & $10(12.5)$ & 6.56 & $<0.01$ \\
- Pain with active shoulder abduction & $10(8.7)$ & $1(1.25)$ & Fisher & $<0.05$ \\
- Pain in the C5 or C6 dermatome regions. & $22(19.1)$ & $6(7.5)$ & 5.19 & $<0.05$ \\
\hline Signs: & $26(22.6)$ & $8(10.5)$ & 5.21 & $<0.05$ \\
- Pain at resisted abduction of arm & $18(15.6)$ & $2(2.5)$ & 8.87 & $<0.01$ \\
- Tenderness of greater humeral tubercle & - Impingement sign &
\end{tabular}

Table (4): Means and standard deviations of shoulder function score among the study workers

\begin{tabular}{|c|c|c|c|c|c|c|}
\hline Shoulder function score & $\begin{array}{l}\text { Healthy } \\
\text { Workers }\end{array}$ & $\begin{array}{l}\text { With SIS } \\
\text { symptoms }\end{array}$ & $\begin{array}{c}\text { With } \\
\text { diagnosed SIS }\end{array}$ & P1 & P2 & P3 \\
\hline Slaughterhouse workers $(\mathrm{n}=115)$ & $(n=65)$ & $(n=32)$ & $(n=18)$ & & & \\
\hline -Total Score X \pm SD & $92.2 \pm 5.8$ & $86.6 \pm 9.6$ & $62.3 \pm 7.4$ & $>0.05$ & $<0.001$ & $<0.001$ \\
\hline -Pain and activities $\mathrm{X} \pm \mathrm{SD}$ & $32.2 \pm 2.5$ & $29.7 \pm 4.2$ & $20.5 \pm 3.6$ & $>0.05$ & $<0.001$ & $<0.001$ \\
\hline -Range of motion $\mathrm{X} \pm \mathrm{SD}$ & $38.4 \pm 1.2$ & $37.3 \pm 3.1$ & $29.4 \pm 2.3$ & $>0.05$ & $<0.001$ & $<0.001$ \\
\hline -Strength $\mathrm{X} \pm \mathrm{SD}$ & $21.6 \pm 2.1$ & $19.6 \pm 2.3$ & $12.4 \pm 1.5$ & $>0.05$ & $<0.001$ & $<0.001$ \\
\hline$\overline{\text { Control workers }\left(\mathrm{n}=70^{*}\right)}$ & $(\mathrm{n}=58)$ & $(\mathrm{n}=10)$ & $(n=2)$ & & & \\
\hline -Total Score $X \pm S D$ & $90.5 \pm 6.3$ & $83.9 \pm 6.9$ & $63.3 \pm 2.5$ & $>0.05$ & $<0.001$ & $<0.01$ \\
\hline -Pain and activities $\mathrm{X} \pm \mathrm{SD}$ & $31.2 \pm 1.9$ & $29.1 \pm 2.1$ & $20.5 \pm 0.7$ & $>0.05$ & $<0.001$ & $<0.01$ \\
\hline -Range of motion $\mathrm{X} \pm \mathrm{SD}$ & $38.9 \pm 1.9$ & $37.0 \pm 2.3$ & $32.5 \pm 0.7$ & $>0.05$ & $<0.001$ & $<0.01$ \\
\hline -Strength $\mathrm{X} \pm \mathrm{SD}$ & $20.4 \pm 2.5$ & $17.8 \pm 2.5$ & $11.3 \pm 1.1$ & $>0.05$ & $<0.001$ & $<0.01$ \\
\hline
\end{tabular}

P1 = Healthy workers vs workers with SIS symptoms.

$\mathrm{P} 2=$ Healthy workers vs workers with diagnosed SIS.

P3 = Workers with SIS symptoms vs workers with diagnosed SIS.

* Functional measures were incomplete for 10 control workers 
Table (5): Shoulder impingement syndrome according to MRI findings in the study workers.

\begin{tabular}{|c|c|c|c|c|}
\hline \multirow[t]{2}{*}{ MRI findings } & \multicolumn{2}{|c|}{$\begin{array}{l}\text { Slaughterhouse } \\
\text { workers } n=18\end{array}$} & \multicolumn{2}{|c|}{$\begin{array}{l}\text { Control workers } \\
\qquad n=2\end{array}$} \\
\hline & No & $\%$ & No & $\%$ \\
\hline -Indentations upon subacromial fat denoting impingement (SIS) & 12 & 66.7 & 0 & 0.0 \\
\hline $\begin{array}{l}\text {-Signal intensity upon supraspinatus tendon with indentation upon subacro- } \\
\text { mial fat denoting tendonitis with impingement(SIS) }\end{array}$ & 4 & 22.2 & 2 & 100.0 \\
\hline - Supraspinatus tear & 2 & 11.1 & 0 & 0.0 \\
\hline Total & & 100.0 & 2 & 100.0 \\
\hline
\end{tabular}
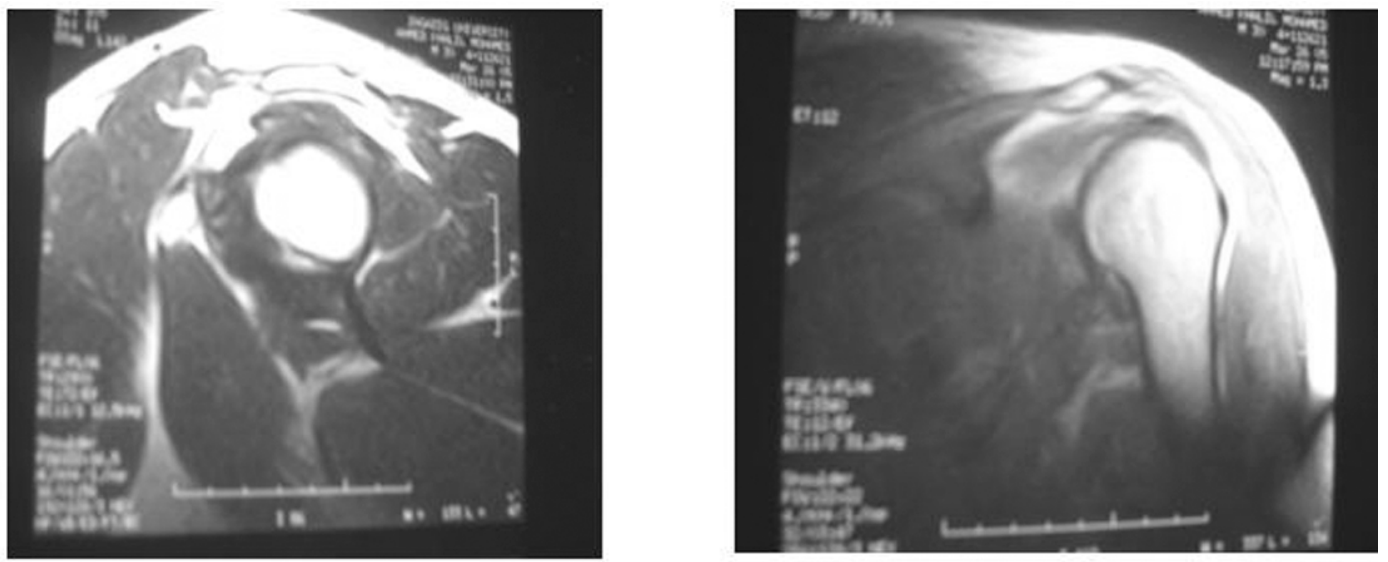

Fig 2: MR imaging of the Left. Shoulder of 38 years old slaughterhouse worker with subacromial impingement. Sagittal T,WI, STIR revealed.

- Indentation upon subacromial fat due to muscle impingement.

- Mininal joint effusion.

- Subdeltoid bursal fluid collection. 

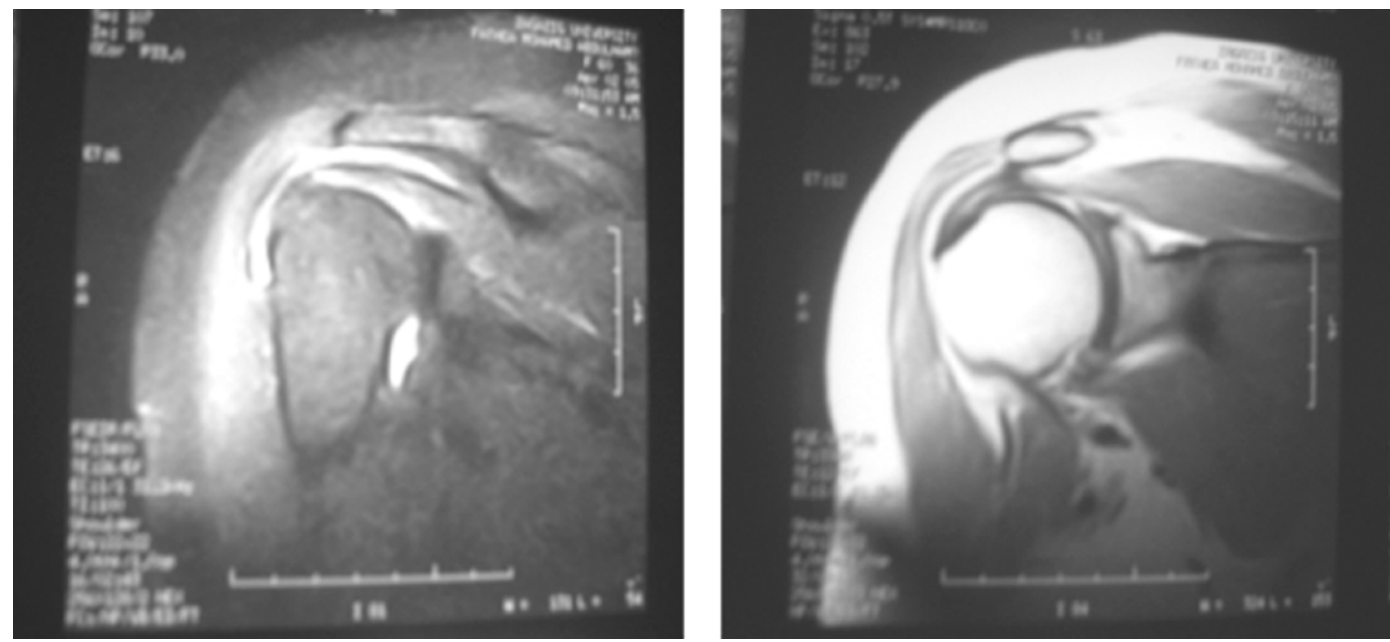

Fig 3: MR imaging of the Rt. Shoulder of 40 years old slaughterhouse worker with supraspinatus tendonitis and impingement. Coronal T,WI, STIR revealed.

- evidence of intermediate signal intensity involving the Rt. Supraspinatus tendon denoting tendonitis.

- Mild indentation upon subacromial fat denoting impingement.

Table (6): Relation between some personal \& occupational factors and SIS among slaughterhouse workers.

\begin{tabular}{|c|c|c|c|}
\hline \multirow{2}{*}{ Characteristics } & $\begin{array}{c}\text { Slaughterhouse work- } \\
\text { ers with SIS } \\
\mathrm{n}=16\end{array}$ & $\begin{array}{c}\text { Slaughterhouse work- } \\
\text { ers without SIS } \\
\mathrm{n}=99\end{array}$ & \multirow{2}{*}{ OR(95\%CI) } \\
\cline { 2 - 3 } & No (\%) & No $(\%)$ & \multirow{2}{*}{1.0} \\
\hline Age (Y) & $1(3.3)$ & $29(96.6)$ & $8.79(1.04-394.2)^{*}$ \\
$<30$ & $10(23.2)$ & $33(76.7)$ & $3.92(0.4-191.63)$ \\
$30-$ & $5(11.9)$ & $37(88.1)$ & $4.08(1.02-23.42)^{*}$ \\
$>40$ & $3(5.9)$ & $48(94.1)$ & \\
\hline Smoking & $13(20.3)$ & $51(79.7)$ & $4.42(1.11-25.37)^{*}$ \\
Sonsmokers & $3(5.7)$ & $50(94.3)$ & \\
\hline Duration of work & $13(21.0)$ & $49(79.0)$ & \\
$<10$ & \multicolumn{2}{|}{} \\
\hline
\end{tabular}

$* \mathrm{P}<0.05$ 
Table (7): Shoulder function score before and after the exercise and manual therapy program among workers with SIS.

\begin{tabular}{|l|c|c|c|}
\hline $\begin{array}{l}\text { Shoulder } \\
\text { Function score }\end{array}$ & $\begin{array}{c}\text { Before Exercise and } \\
\text { manual therapy } \\
\mathrm{n}=12\end{array}$ & $\begin{array}{c}\text { After Exercise and } \\
\text { manual therapy } \\
\mathrm{n}=12\end{array}$ & P- value \\
\cline { 2 - 3 } & $\mathrm{X} \pm \mathrm{SD}$ & $\mathrm{X} \pm \mathrm{SD}$ & \\
\hline Total score & $67.6 \pm 15.3$ & $83.8 \pm 14.4$ & $<0.01$ \\
\hline Pain and activities & $20.6 \pm 4.7$ & $27.8 \pm 5.4$ & $<0.01$ \\
\hline Range of motion & $31.9 \pm 6.6$ & $37.9 \pm 4.3$ & $<0.01$ \\
\hline Strength & $15.1 \pm 4.5$ & $18.1 \pm 4.7$ & $<0.05$ \\
\hline
\end{tabular}

\section{Discussion}

Shoulder impingement syndrome is the most prevalent problems among shoulder disorders ${ }^{(32)}$ and has a high occurrence in many occupations. In our study, the prevalence of SIS among slaughterhouse workers was $13.9 \%$ compared to $2.5 \%$ among the control group. In fact the prevalence of SIS varies in different studies , it was 5.8\% among female sewing machine operators ${ }^{(33)}, \quad 8.7 \%$ among slaughterhouse workers ${ }^{(22)}, 12 \%$ among women with repetitive industrial work ${ }^{(34)}$, $15 \%$ among women in the fish processing industry $^{(35)}$ and brick layers ${ }^{(18)}$ and $40 \%$ among rock blasters ${ }^{(18)}$.

The difference observed in the prevalence of SIS between our slaughterhouse workers and workers in the other studies are probably reflected the differences in the criteria used for case definitions and methods of examination. Most researchers define cases by clinical examination (symptoms and clinical findings), but some use clinical findings without symptoms and vise versa. Our definition of SIS was strict where a definite criteria ${ }^{(26)}$ for diagnosis was based on positive impingement test with a total shoulder function score of 64 and confirmed by MRI.

It appear that the prevalence of SIS in the referent groups was similar across studies $^{(18-22-33-36)}$, expect when the most lenient diagnostic criteria was applied ${ }^{(17)}$.

In our study, slaughterhouse workers are exposed to repetitive shoulder movement, sustained arm elevation of meat products of different weights. Frost \& Anderson $^{(22)}$ and Armstrong et al. ${ }^{(37)}$ reported that during elevation of the arm, at or above 30 degrees, the rotator cuff tendons and the insertions on the greater tuberosity are compressed under the coracoacromial arch (acromion \& coracoacromial liga- 
ment)and this compress-ion or impingement is sufficient to impair perfusion of the tendon. But if these combined exertions and their responses in the tissues are long lasting, it has been argued that inflammation, degeneration, and eventually rupture of the shoulder tendons may result ${ }^{(37)}$. Also some studies ${ }^{(37,38)}$ reported that overuse injury of the rotator cuff as repetitive motion of the arms, heavy lifting and work with arms above the shoulder level can lead to thickening of coracoacromial ligament, osteophytes formation under the surface of acromioclavicular joint, failure or fatigue of the rotator cuff and swelling of the rotator cuff and subacromial bursa. All these factors can reduce the subacromial space with subsequent increasing the potential risk of impingement ${ }^{(16)}$.

In this study, SIS symptoms and signs were significantly more frequent among the slaughterhouse workers and were similar to those in the other studies ${ }^{(6,16,38)}$. Also repetitive use of a knife (repetitive forceful movement) ${ }^{(39)}$, increased level of muscle activity with few periods of low activity (micro pauses) or lack of sufficient rest during repetitive movements of the arms ${ }^{(40)}$, and working with arms at or above shoulder level ${ }^{(41,42)}$ may result in shoulder pain.
In our study, there was loss of some functional ability of the shoulder such as range of motion among slaughterhouse workers than the control group. This is in accordance with Kibler et al. ${ }^{(43)}$ who reported that shoulder motion is due to the simultaneous participation of glenohumeral, sternoclavicular, acromioclavicular and scapulothoracic articulations. Any injury to these structures or those that support them may cause pain or loss of functional ability such as range of motion and strength which will create a cycle of further pain, anatomic changes, and decreased performance.

The most reliable findings of MR imaging in this study were identations upon the subacromial fat denoting impingement and signal intensity changes involving the supraspinatus tendon denoting tendonitis. This in accordance with Padron and Beltron $^{(44)}$ who reported that the ability of MRI to display shoulder anatomy and detect subtle soft tissue changes is very valuable for diagnosis of rotator cuff pathology. This is in agreement with our MRI study which recorded 16 cases of impingement and 2 cases of supraspinatus tendon tear among 18 slaughterhouse workers with positive impingement sign. Moreover, Svendsen et al. ${ }^{(45)}$ in their MRI study of degenerative alternations of the rotator 
cuff tendons in case of work above shoulder level, reported supraspinatus, infraspinatus and subscapularis tendinopathies which were evidenced by signal intensity changes and morphologic alternations.

Studying the effect of some worker's characteristics on SIS revealed that, SIS is prevalent among the middle aged workers, which means that rotator cuff are not due to aging process , but are thought to be occupationally related. This is accordance with Frost and Anderson ${ }^{(22)}$ who stated that the risk of impingement syndrome was highest among former slaughterhouse workers.

Smoking has been identified as being significantly related to SIS. A similar association has been reported previously by Stendlund et al. ${ }^{(18)}$ who suggested that nicotine induces vasoconstriction of small nutrient vessels, reduce blood flow to the shoulder and may affect the tendon perfusion. In contrast, no association with smoking had been found ${ }^{(22)}$.

There is a marked association of SIS with the duration of work in our study. This is in accordance with other studies ${ }^{(18,34,46)}$. On the other hand Frost and Anderson ${ }^{(22)}$ reported that the risk of SIS increases steeply within the first 5-6 years of exposure then tend to flatten after 9 years until a new increase gradually develops after about 25 years of exposure. In contrast, ViikariJuntura $^{(47)}$, in a study on Finnish slaughterhouse workers, found three cases of supraspinatus and one case of biceps tendonitis among 113 workers but with short duration of employment.

Regarding the study of intervention program, our data agree with those of other researchers $(30,48,49,50)$ who have documented improvements in impairments and function of the shoulder following an exercise program in patients with shoulder impingement syndrome. Also Michener et al. ${ }^{(51)}$ reported that therapeutic exercise was the most widely studied form of physical intervention and demonstrated shortterm and long-term effectiveness for decreasing pain and reducing functional loss. As Bang and Deyle ${ }^{(30)}$ followed patients for 6 visits over 3 weeks and found that patients who received manual therapy and exercise ,demonstrated greater short improvements in muscle stength and pain than those who received exercise only. McClure et al. ${ }^{(2)}$ demonstrated short and long term improvements in pain, satisfaction and function, where they applied a simple home intervention program with a low number of weekly coaching and minor modification visits.

Although different measures of pain and function were used in different previ- 
ous studies of SIS where placebo or no intervention was compared with other interventions $^{(30,48)}$, they suggest that pain associated with impingement does not spontaneously resolve and may even worsen slightly with no intervention or placebo. And without active intervention, shoulder function showed a decline in some studies $(30,48)$ and did not improve in other ${ }^{(52)}$.

In our study, we found that the ability to move the thumb up the back, as a measure of internal rotator, improve by almost 2 vertebral level . Internal rotation is believed to reflect the length of the glenohumeral joint posterior capsules, and tightness of this structure has been shown to promote anterior-superior translation of the humeral head consistent with subacromial improvement ${ }^{(9)}$. Other researchers ${ }^{(53)}$ also have pointed out that measuring medial rotation by vertebral level incorporates elbow motion and substantial scapulothoracic motion. We have to use this measure primarily because patients with impingement are often unable to tolerate internal rotation with the arm elevated to 90 degrees. In addition, placing the hand behind the back appears to be important for several functional activities such as tucking in a shirt or toileting functions. Determining the optimal way to document tightness of the posterior capsule is the optimal way to improve it with stretching, as we believe , are worthy of further study.

In conclusion, sustained intensive manual work such as repetitive shoulder movements, sustained arm elevation and repetitive handling of different weights as in slaughterhouse workers is associated with high frequency of SIS. Also SIS frequency was related to some factors as age, smoking and duration of work. A 6 week exercise with manual therapy program in a group of patients with SIS resulted in improvement of motion, pain and function of the shoulder. So, ergonomic education, work organization with reduction of exposure time, surveillance for SIS in the work place and early intervention are needed in tasks in which combinations of force, repetition and sustained arm elevation are hard to be prevented.

\section{References}

1- Neer C.S. II ( 1972): Anterior acromioplasty for the chronic impingement syndrome in the shoulder. J Bone Surg Am;54:41-50.

2- McClure P.W., Bialker J., Neff N., Williams G. and Karduna A. (2004): Shoulder function and 3- dimensional kinematics in people with shoulder impingement syndrome before and after a 6week exercise program. Phy Ther ; 84 (9) : 832-848.

3- Van der Windt D.A., Koes B.W., de Jong B.A., Bouter L.M. (1995): Shoulder disorders in general practice : incidence, patient characteristics 
and management. Ann Rheum Dis ; 54 : 959964.

4- Cofield R.H. (1985): Rotator cuff disease of the shoulder. J Bone Joint Surg Am ;67: 974979.

5- Neer C.S. II (1983): Impingement lesions. Clin Orthop ;173: 70- 77 .

6- Koopman W.J. and McCurty D.J. (1997): Regional disorders of joints and related structures. Impingement syndrome. In Arthritis and Allied Conditions. 13th ed. Philadelphia ; 101 : 18931896.

7-Altchek D.W., warren R.F., Wickiewicz T.L. (1990): Arththroscopic acromio plasty: technique and results . J Bone Joint surg Am ; 721198-1207.

8-Bigliani L.U., Levine W.N. (1997): subacromial impingement syndrome. J Bone Joint Surg Am ; 79: 1854-1868.

9-Harryman D.T. II , sidles J.A., Clark J.M. (1990): Translation of the humeral head on the glenoid with passive gleno humeral motion. J Bone Joint surg Am; 172 : 1334-1343.

10-Warner J.J., Micheli L.J., Arslanian L.E. (1990): Patterns of flexibility, laxity, and strength in normal shoulders and shoulders with instability and impingement. Am $\mathrm{J}$ sports Med; 18 : 366-375.

11-Tyler T.F., Nicholas S.J., Roy T., Gleim G.W. (2000): Quantification of posterior capsule tightness and motion loss in patients with shoulder impingement. Am J sports Med ; 28 : 668-673.

12-LOYP, Hsu Y.C., chan K.M. (1990): Epidemiology of shoulder impingement in upper arm sports events. Br J sports Med ; 24:173-177.

13-Bu-doff J.E., Nirschl R.P., Guidi E.J. (1998): De- bridement of partial-thickness tears of the rotator cuff without acromio-plasty :Long-term follow-up and review of the literature $\mathrm{J}$ Bone Joint Surg Am ;80:733-748.

14-Miranda H., Viikari-Juntura E., Martikainen R. (2001): A prospective study of work related factors and physical exercise as predictors of shoulder pain . Occup. Environ. Med ; 58 : 528-534.

15-Frost P., Bonde J.P., Mikkelsen S. (2002): Risk of shoulder tendonitis in relation to shoulder loads in monotonous repetitive work. Am $\mathrm{J}$ Ind Med ; $41: 11-18$.

16-Strakowski J.A., Wiand W. and Johnson E.W. (2000): Upper limb musculoskeletal pain syndromes. Rotator cuff disease .In: Braddom RL ,ed. Physical Medicine and Rehabilitation 2nd ed. Philadelphia :WB Saunders Co : 792-799.

17- Kelley M.J., and Clark W.A. (1995): Impingement syndrome . In : Orthoprdic Therapy of the Shoulder. Lippencot Co Philadelphia:108-113.

18- Stendlund B., Goldie I. and Hagberg M. (1993): Shoulder tendonitis and its relation to heavy manual work and exposure to vibration. Scand $\mathbf{J}$ Work Environ Health ; 19 : 43-9.

19- Punnett L., Fine L.J., Keyserling W.M.(2000): Shoulder disorders and postural stress in automobile assembly work. Scand J Work Environ Health ; 26 : 283-9.

20- Niedhammer I., Landre M.F. and Leclerc A. (1998): Shoulder disorders related to work organization and other occupational factors among supermarket cashiers. Int $\mathbf{J}$ Occup Environ Health ; 54: 168-78.

21- Schibye B., Skov T. and Ekner D. (1995): Musculoskeletal disorders of the neck and upper limb among sewing machine operators. Scand J Work Environ Health ; 21 : 427-35. 
22- Frost P. and Anderson J.H. (1999) : Shoulder impingement syndrome in relation to shoulder intensive work. Occup Environ Med ; 56 : 4948.

23- Chiang H.C., Ko Y.C. and Chen S.S. (1993): Prevalence of shoulder and upper limb disorders among workers in the fish processing industry. Scand J Work Environ Health ;19 : 126-31.

24- Matsen F.A. III and Arntz C.T. (1990) : Subacromial impingement. In : Rockwood CA Jr, Matsen FA III,eds. The Shoulder. Vol 2. Philadelphia, Pa : WB Saunders Co : 623 ñ646.

25- kourinka I., Jonsson B. and Kilbom A. (1987): Standerdised Nordic Questionnaires for the analysis of musculoskeletal symptoms. Applied Ergonomics ; $18: 233-7$.

26- McClure P.W., Michener L.A. and Karduna A.R. (2006): Shoulder function and 3dimensional scapular kinematics in people with and without shoulder impingement syndrome. Phys Ther Aug ; 86 (8) :1075-90.

27- Brotzman B. and Wilk K.E. (2003) : Shoulder injuries . In : Clinical Orthopaedic Rehabilitation . 2nd ed. Mosby Philadelphia ;3 : 145-155.

28- Constant C.R. (1991): Assessment of the shoulder. In :Watson M. Surgical disorders of the shoulder. Churchill Living Stone, New York ; 39-45.

29- Seeger L.L., Gold R.H., and Basst L.W. (2001): Shoulder instability : evaluation with MR imagings. Radiology ; 150 : 342-346.

30- Bang M., and Deyle G.D. (2000): Comparison of supervised exercise with or without manual physical therapy for patients with shoulder impingement syndrome. J Ortho Sports Phys Ther ; $30: 126-137$.
31- Norusis M. (1997): Statistical Pakage for Social Science (SPSS) base 8.0 for windows user,s Guid. Chichago IL : SPSS.

32- Johansson K.M., Adolfsson L.E., and Foldevi M.O. (2005): Effects of acupuncture versus ultrasound in patients with impingement syndrome : Randomized clinical trial. Phy Ther ; 85 (6) : 490-501.

33- Kaergaard A. and Anderson J.H. (2000) : Musculoskeletal disorders of the neck and shoulders in female sewing machine operators :prevalence, incidence, and prognosis. Occup Environ Med ; 57 : 528-34.

34- Ohlsson K., Attewell R.G. and Palsson B. (1995): Repetitive industrial work and neck and upper limb disorders in females. Am J Ind Med ; 27 : 731-47.

35- Ohlsson K., Hansson G.A., Belogh I., Stromberg U., Pailson B., Nordander C., Rylander L. and Skerfring S. (1994) : Disorders of the neck and upper limbs in women in the fish processing industry .Occup Environ Med ; 51 : 826-32.

36- Frost P., Bonde J.P., and Mikkelsen S. (2002) : Risk of shoulder tendonitis in relation to shoulder loads in monotonous repetitive work. Am J Ind Med ; $41: 11-18$.

37- Armstrong T.J., Buckle P., and Fine L.J. (1993): A conceptual model for work- related neck and upper limb musculoskeletal disorders. Scand J Work Environ Health ; 19 : 73-84.

38- Svendsen S.W., Bonde J.P., Mathiassen S.E., Stengaard- Pedersen K., and Frich L.H. (2004) : Work related shoulder disorders : quantitative exposure response relations with reference to arm posture. Occup Environ Med ; 61 : 844853. 
39- Leclere A., Chasting J.F., Niedhammer I., Landre M.F. and Roquelaure Y. (2004): Incidence of shoulder pain in repetitive work. BMJ; 61: $39-44$.

40- van der Windt D.A., Thomas E., Pope D.P., de Winter A.F., Macfarlane G.J., Bouter L.M. and Sliman A.J. (2000): Occupational risk factors for shoulder pain : a systemic review. OEM ; 57 : 433-442.

41- Pope D.P., Croft P.R., Ptitchard C.M., Sliman A.J. and Macfarlane G.J. (1997): Occupational factors related to shoulder pain and disability. Occup Environ Med ; 54 : 316-321.

42- Sommerich C.M., McGlothlin J.D., and Marras W.S. (1993): Occupational risk factors associated with soft tissue disorders of the shoulder : a review of recent investigations in the literature. Ergonomics ; 36 : 697-717.

43- Kibler W.B. (1998): Role of the scapula in athletic shoulder function. Am J Sports Med ; 26 :325-337.

44- Padron M. and Beltron J. (2001): MRI of the shoulder, musculoskeletal imaging : an update ; 23-24.

45- Svendsen S.W., Gelineck J., Mathiassen S.E., Bonde J.P., Frich L.H., Persen K.S., and Egund N. (2004) : Work above shoulder level and degenerative alternations of the rotator cuff tendons : A magnetic resonance imaging study. Arthr \& Rheum J ; $50: 3314-3322$.

46- Brisson C., Vinet A., Vezina M. and Glingras S. (1989): Effect of duration of employment in piece work on severe disability among female garment workers. Scand J Work Environ Health ; 15 : 329-34.
47- Viikari-Juntra E. (1983): Neck and upper limb disorders among slaughterhouse workers. An epidemiological and clinical study. Scand J Work Environ Health ; $9: 283-90$.

48- Brox J.I., Staff P.H., Ljunggren A.E. and Brevik J.I. (1993): Arthroscopic surgery compared with supervised exercises in patients with rotator cuff disease. B M J ; 307 (6909) : 899-903.

49- Dorrestijn O., Stevens M., Diercks R.L., Van der Meer K. and Winters J.C. (2007): A new interdisciplinary treatment strategy versus usual medical care of the treatment of subacromial impingement syndrome: a randomized controlled trial. BMC Musculoskeletal Disord ; 8 (1) : 15 $\{\mathrm{E}$ pub ahead of print $\}$.

50- Jonsson P., Walstrom P., Ohberg L. and Alfredson H. (2006): Eccentric training in chronic painfull impingement syndrome of the shoulder : results of a pilot study. Knee Surg Sports Troumatol Arthrosc ; 14 (1) : 76-84.

51- Michener L.A., Walsworth M.K., and Burnet E.N. (2005): Effectiveness of rehabilitation for patients with subacromial impingement syndrome. A systemic review. J Hand Ther; 17 : 152-164.

52- Blair B., Rokito A.S., and Cuomo F. (1996): Efficacy of infections of corticosteroids for subacromial impingement syndrome. J Bone Joint Surg Am ; 78 : 1685-1689.

53- Mallon W.J., Herring C.L. and Sallay P.I. (1996): Use of vertebral levels to measure presumed internal rotation at the shoulder. a radiographic analysis. J Shoulder Elbow Surg ; 5 : 299-306. 